\title{
Mesosphere-to-stratosphere descent of odd nitrogen in February-March 2009 after sudden stratospheric warming
}

\author{
S.-M. Salmi ${ }^{1,2}$, P. T. Verronen ${ }^{1}$, L. Thölix ${ }^{1}$, E. Kyrölä ${ }^{1}$, L. Backman ${ }^{1}$, A. Yu. Karpechko ${ }^{1}$, and A. Seppälä ${ }^{1,3}$ \\ ${ }^{1}$ Finnish Meteorological Institute, Helsinki, Finland \\ ${ }^{2}$ Department of Physics, University of Helsinki, Helsinki, Finland \\ ${ }^{3}$ British Antarctic Survey (NERC), Cambridge, UK
}

Received: 23 November 2010 - Published in Atmos. Chem. Phys. Discuss.: 18 January 2011

Revised: 27 April 2011 - Accepted: 5 May 2011 - Published: 18 May 2011

\begin{abstract}
We use the 3-D FinROSE chemistry transport model (CTM) and Atmospheric Chemistry Experiment Fourier Transform Spectrometer (ACE-FTS) observations to study connections between atmospheric dynamics and middle atmospheric $\mathrm{NO}_{\mathrm{x}}\left(\mathrm{NO}_{\mathrm{x}}=\mathrm{NO}+\mathrm{NO}_{2}\right)$ distribution. Two cases are considered in the northern polar regions: (1) descent of mesospheric $\mathrm{NO}_{\mathrm{x}}$ in February-March 2009 after a major sudden stratospheric warming (SSW) and, for comparison, (2) early 2007 when no $\mathrm{NO}_{\mathrm{x}}$ descent occurred. The model uses the European Centre for Medium-Range Weather Forecasts (ECMWF) operational data for winds and temperature, and we force $\mathrm{NO}_{\mathrm{x}}$ at the model upper altitude boundary $(80 \mathrm{~km})$ with ACE-FTS observations. We then compare the model results with ACE-FTS observations at lower altitudes. For the periods studied, geomagnetic indices are low, which indicates absence of local $\mathrm{NO}_{\mathrm{x}}$ production by particle precipitation. This gives us a good opportunity to study effects of atmospheric transport on polar $\mathrm{NO}_{\mathrm{x}}$. The model results show no $\mathrm{NO}_{\mathrm{x}}$ descent in 2007, in agreement with ACE-FTS. In contrast, a large amount of $\mathrm{NO}_{\mathrm{x}}$ descends in February-March 2009 from the upper to lower mesosphere at latitudes larger than $60^{\circ} \mathrm{N}$, i.e. inside the polar vortex. Both observations and model results suggest $\mathrm{NO}_{\mathrm{x}}$ increases of $150-200 \mathrm{ppb}$ (i.e. by factor of 50 ) at $65 \mathrm{~km}$ due to the descent. However, the model underestimates the amount of $\mathrm{NO}_{\mathrm{x}}$ around $55 \mathrm{~km}$ by $40-60 \mathrm{ppb}$. According to the model results, chemical loss of $\mathrm{NO}_{\mathrm{x}}$ is insignificant during the descent period, i.e. polar $\mathrm{NO}_{\mathrm{x}}$ is mainly controlled by dynamics. The descent is terminated and the polar $\mathrm{NO}_{\mathrm{x}}$ amounts return to pre-descent levels in mid-March, when the polar vortex breaks. The break-up prevents the descending $\mathrm{NO}_{\mathrm{x}}$ from reaching the upper stratosphere, where it could participate in catalytic ozone destruction. Both ACE-FTS observa-
\end{abstract}

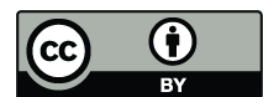

Correspondence to: S.-M. Salmi (sanna-mari.salmi@fmi.fi) tions and FinROSE show a decrease of ozone of 20-30\% at $30-50 \mathrm{~km}$ from mid-February to mid-March. In the model, these ozone changes are not related to the descent but are due to solar activation of halogen and $\mathrm{NO}_{\mathrm{x}}$ chemistry.

\section{Introduction}

In the stratosphere odd nitrogen $\left(\mathrm{NO}_{\mathrm{x}}=\mathrm{NO}+\mathrm{NO}_{2}\right)$ is produced mainly by oxidation of nitrous oxide $\left(\mathrm{N}_{2} \mathrm{O}\right)$. Significant production occurs also in the lower thermosphere, around $110 \mathrm{~km}$, through photoionization of $\mathrm{N}_{2}$ by extreme ultraviolet (EUV) and soft X-ray radiation. In the polar regions, another important and highly varying source of $\mathrm{NO}_{\mathrm{x}}$ is ionizing energetic particle precipitation directly affecting a wide range of altitudes from the thermosphere down to the stratosphere (Barth, 1992; Vitt et al., 2000). Because $\mathrm{NO}_{\mathrm{x}}$ loss is driven by photodissociation, in the absence of solar radiation $\mathrm{NO}_{\mathrm{x}}$ is chemically long-lived and therefore strongly affected by atmospheric dynamics.

In the recent years, observations have shown that during winter times $\mathrm{NO}_{\mathrm{x}}$ can be effectively transported downwards inside the polar vortex (Funke et al., 2005, 2007; Hauchecorne et al., 2007; Seppälä et al., 2007; Randall et al., 2009), after $\mathrm{NO}_{\mathrm{x}}$ is produced by particle precipitation in the mesosphere-lower thermosphere (MLT). Although the satellite observations of $\mathrm{NO}_{\mathrm{x}}$ often cover altitudes up to middle mesosphere only, the connection to lower thermospheric $\mathrm{NO}_{\mathrm{x}}$ production has been established using VLF (Very Low-Frequency) radio propagation data in the case of the 2004 descent event (Clilverd et al., 2006). Previously it had already been suggested that $\mathrm{NO}_{\mathrm{x}}$ transport could provide a connection mechanism between particle precipitation in the MLT region and stratospheric ozone (Solomon et al., 1982; Siskind et al., 1997; Callis and Lambet, 1998). Several recent studies based on atmospheric modelling support the importance of wintertime $\mathrm{NO}_{\mathrm{x}}$ enhancements to middle

Published by Copernicus Publications on behalf of the European Geosciences Union. 
atmospheric composition (Vogel et al., 2008; Baumgaertner et al., 2009; Reddmann et al., 2010). Callis et al. (2000) suggested that changes in $\mathrm{NO}_{\mathrm{x}}$ concentrations due to particle precipitation and variations in transport could have a comparable effect on the amount of ozone in the upper stratosphere as changes in UV radiation at lower latitudes. At middle to high latitudes this coupling between $\mathrm{NO}_{\mathrm{x}}$ and ozone may have a significant effect, again comparable in magnitude to that of UV radiation, also on the dynamics (Callis et al., 2001; Langematz et al., 2005). It has even been suggested that these changes could affect the polar regional ground-level climate although the linking mechanisms are not yet understood (Rozanov et al., 2005; Seppälä et al., 2009; Baumgaertner et al., 2010). Also other mechanisms connecting geomagnetic activity and middle atmospheric dynamics have been proposed. Arnold and Robinson (2001) suggested a coupling of geomagnetic activity to atmospheric waves. Lu et al. (2008) suggested that geomagnetic and far-UV perturbations might have an indirect connection to the stratosphere. Along the lines of Arnold and Robinson (2001), Lu et al. (2008) also concluded that this is likely due to coupling between the mean flow and atmospheric waves. Satellite observations have shown that exceptionally strong $\mathrm{NO}_{\mathrm{x}}$ descent events occurred in 2004, 2006 and 2009 after sudden stratospheric warming events (Randall et al., 2009; Manney et al., 2009). These events are related to reformation of the vortex following its split/displacement. One of the strongest major SSWs on record occurred in the Northern Hemisphere in January 2009 (Manney et al., 2009). According to observations of the Microwave Limb Sounder (MLS), the stratopause broke down in late January and then reformed at very high altitudes around $80 \mathrm{~km}$. During the major SSW the polar vortex split, but reformed after the SSW in the upper stratosphere where it became stronger than it initially was. Randall et al. (2009) used ACE-FTS data and showed that following the SSW stratospheric $\mathrm{NO}_{\mathrm{x}}$ increased due to strong downward transport by factor of approximately 50 compared to winters without descent events. Because geomagnetic activity was low at the time, indicating that there was no significant $\mathrm{NO}_{\mathrm{x}}$ production by particle precipitation occurring, the $\mathrm{NO}_{\mathrm{x}}$ enhancement in 2009 was likely driven by the meteorology. Randall et al. (2009) further concluded that significant effects on ozone were neither expected nor observed since the descending $\mathrm{NO}_{\mathrm{x}}$ enhancements never reached altitudes where $\mathrm{NO}_{\mathrm{x}}$ is most effective at catalytic ozone destruction. However, they also pointed out the limitations of these conclusions, which were based on data not covering the whole polar night region.

In this paper we analyse the dynamics and meteorology of the winter of 2009 in the northern polar region using ECMWF operational analyses. Building on the observational analysis of Randall et al. (2009), we use the FinROSE chemistry transport model (CTM) to simulate this winter and the strong descent event of $\mathrm{NO}_{\mathrm{x}}$. This is done by constraining the model $\mathrm{NO}_{\mathrm{x}}$ by enforcing a time-dependent upper boundary condition (UBC) based on ACE-FTS observations between 75 and $85 \mathrm{~km}$ altitude. Compared to earlier studies of other $\mathrm{NO}_{\mathrm{x}}$ descent events utilizing ECMWF data (e.g. Vogel et al., 2008; Reddmann et al., 2010), in this study we use ECMWF operational analyses for dynamics up to $80 \mathrm{~km}$, which gives us the opportunity to study the $\mathrm{NO}_{\mathrm{x}}$ descent starting as high as from the upper mesosphere. The 3-dimensional CTM used in this study provides a complete coverage of the polar area, which thus enables also the study of any possible changes in ozone concentrations not seen by ACE-FTS due to its limited spatial coverage. For comparison, we also simulate the winter of 2007 when no comparable SSWs or $\mathrm{NO}_{\mathrm{x}}$ descent was observed.

\section{Model and measurements}

\subsection{Chemistry transport model FinROSE}

FinROSE is a global 3-dimensional CTM designed for middle atmospheric studies (Damski et al., 2007). The model dynamics (i.e. temperature, horizontal winds and pressure) are from external sources i.e. changes in atmospheric composition do not affect the model dynamics. Vertical wind is calculated inside the model by using the continuity equation. In this study FinROSE is run with 41 vertical levels $(0-80 \mathrm{~km})$, a horizontal resolution of $10^{\circ} \times 5^{\circ}$ and is driven by operational analyses from ECMWF. The analyses are based on ECMWF simulations of a general circulation model (GCM) using four dimensional data assimilation (4D-VAR). The horizontal resolution and the number of vertical levels in FinROSE can be modified depending on the resolution of the meteorological data. The model calculates distributions of 40 species and families taking into account both chemistry and dynamics. However, only to the long-lived constituents are transported. The model includes about 120 homogeneous reactions and 30 photodissociation processes. Chemical kinetic data, reaction rate coefficients and absorption cross-sections are taken from look-up-tables based on the Jet Propulsion Laboratory compilation by Sander et al. (2006), including updates from the available supplements. Photodissociation frequencies are calculated using a radiative transfer model (Kylling et al., 1997). In addition to homogeneous chemistry, the model also includes heterogeneous chemistry, i.e. formation and sedimentation of PSCs and reactions on PSCs. Chemistry is not defined in the troposphere, but the tropospheric abundances are given as boundary conditions. At the lower boundary, monthly averages from ECMWF are used for ozone and water vapour, while methane is relaxed towards climatological distribution and other long-lived trace gases towards long time trends.

\subsection{Observations}

We have used observations from the FTS (Fourier Transform Spectrometer) instrument onboard the ACE satellite 


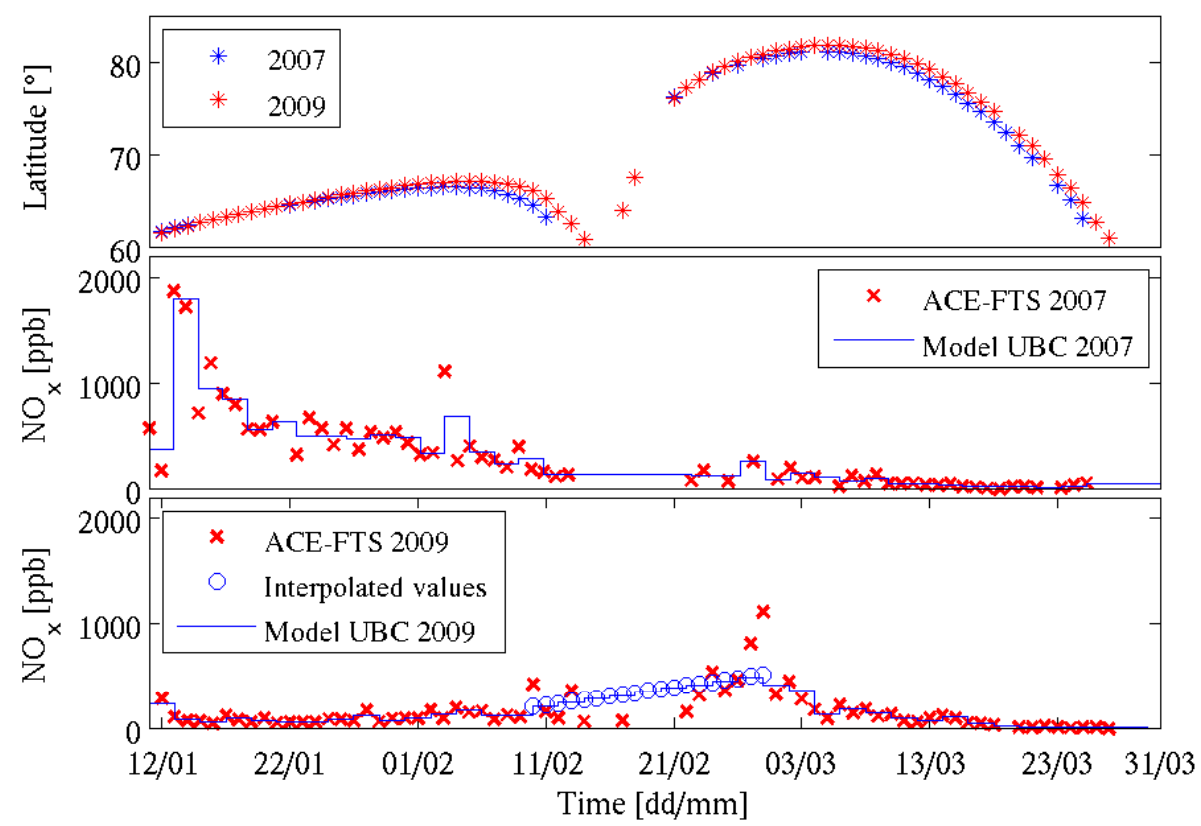

Fig. 1. Daily medians of ACE-FTS measurement locations north of $60^{\circ} \mathrm{N}$ (top) in 2007 (blue asterisk) and 2009 (red asterisk). The figure also shows mean $\mathrm{NO}_{\mathrm{x}}$ concentrations measured by ACE-FTS between $75-85 \mathrm{~km}$ altitudes (red crosses) and two-day means calculated from the observations (blue line) for 2007 (middle) and 2009 (bottom). Two-day means for 2009 are based on interpolated values between 10 and 28 February (blue circles).

(Atmospheric Chemistry Experiment) (Bernath et al., 2005). ACE-FTS is a solar occultation instrument launched in 2003. The instrument operates in the wavelength region of 2.2$13.3 \mu \mathrm{m}$ and measures vertical profiles of temperature, pressure, density and 18 atmospheric constituents in the altitude range of $10-150 \mathrm{~km}$. Figure 1 shows the daily medians of the measurement locations north of $60^{\circ} \mathrm{N}$ in JanuaryMarch 2007 and 2009. We have calculated the median only when there are at least five measurements available during a day. Otherwise the measurements for that particular day have been neglected. In most cases ACE-FTS makes about 10 measurements per day. The figure also shows that the measurements represent almost the same latitudes from year to year. Measuring error for $\mathrm{NO}_{\mathrm{x}}$ depends on altitude and concentration (not shown) so that at $80 \mathrm{~km}$ altitude the error is $1-3 \%$ for mixing ratios such as in late February-early March in 2009 and increases up to $10-15 \%$ for $\mathrm{NO}_{\mathrm{x}}$ amounts observed in January 2009.

In this study we use ACE-FTS observations of $\mathrm{NO}_{\mathrm{x}}$ as an UBC for FinROSE (Fig. 1). We first calculated daily medians from the observations northward of $60^{\circ} \mathrm{N}$ for 2007 and 2009. As a result we got one value per day representing approximately a zonal average at the median latitude. Using these daily values we then calculated two-day means, which we in this study use at the upper boundary of the model. This two-day mean value is used on every time step for two days after which the next two-day mean is used. In case of missing data for both of the days in question, we use the previous two-day mean. The UBC is taken uniform at every grid point between $60^{\circ} \mathrm{N}-90^{\circ} \mathrm{N}$. It should be noted that the instrument changed the direction of the measurements towards lower latitudes after the 5 February, which can be seen as a decrease of about $400 \mathrm{ppb}$ in the $2009 \mathrm{NO}_{\mathrm{x}}$ mixing ratios (Fig. 1). Around 16 February ACE-FTS continued measuring on northern latitudes $\left(>60^{\circ} \mathrm{N}\right)$ and $\mathrm{NO}_{\mathrm{x}}$ concentrations increased because of this. The effect can be seen as a minimum in the $2009 \mathrm{NO}_{\mathrm{x}}$ mixing ratios between 10 and 28 February in Fig. 1. This means that the ACE-FTS measurements do not give a representative general view of the situation in the polar region during this time period. To reduce the influence of the change in the measuring direction, we replaced the 2009 ACE-FTS observations with interpolated values over the minimum (blue circles in Fig. 1) and neglected the largest values. This is somewhat arbitrary, but perhaps the best approach taking into account the lack of usable data in this time period.

\section{Results}

\subsection{Meteorological conditions}

In this section we use the ECMWF operational data to analyse the meteorological conditions and their differences in early 2007 and 2009. We are aware of the possible shortcomings of the data (Manney et al., 2008), but for this study it is important that the ECMWF fields extend up to $80 \mathrm{~km}$, 


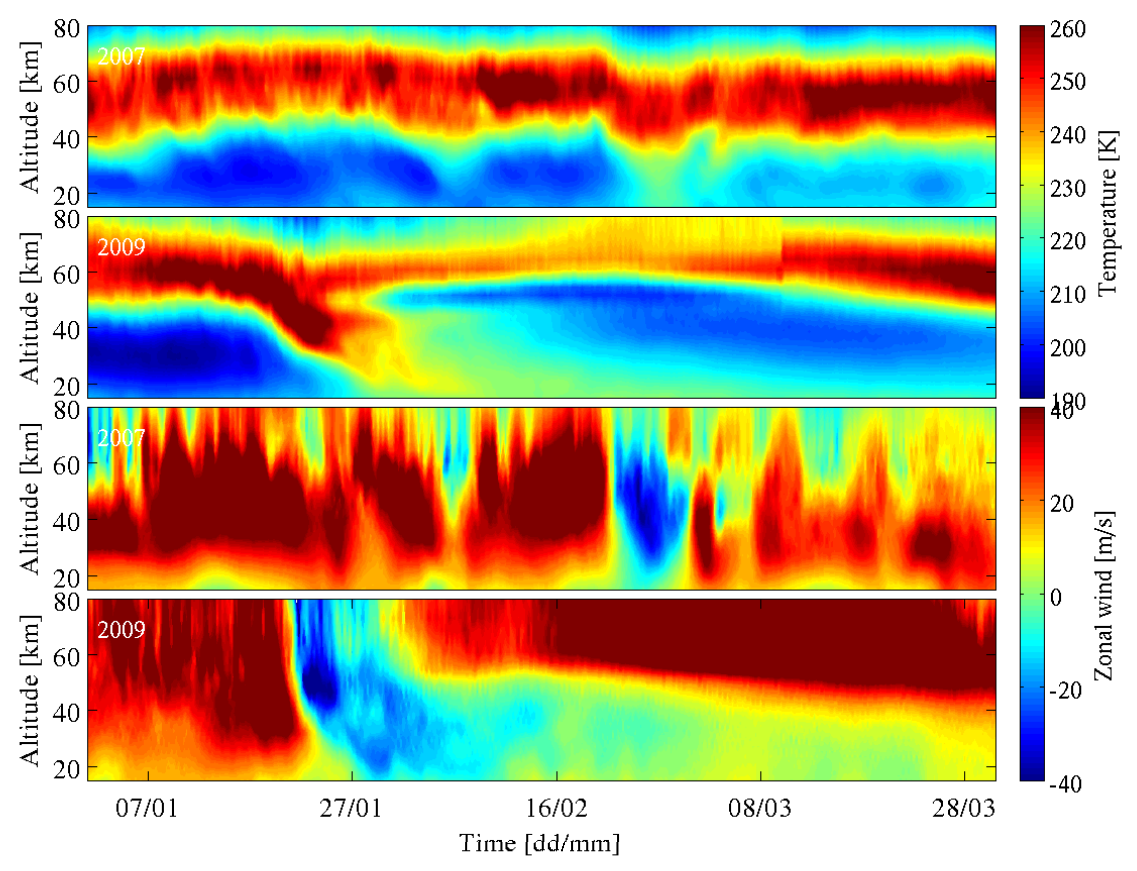

Fig. 2. ECMWF zonal mean temperature $(\mathrm{K})$ and zonal mean zonal wind $\left(\mathrm{m} \mathrm{s}^{-1}\right)$ at $75^{\circ} \mathrm{N}$ as a function of time and altitude for winters 2007 and 2009.

allowing us to model the $\mathrm{NO}_{\mathrm{x}}$ descent starting as high as from the upper mesosphere.

Figure 2 shows zonal mean temperature (two top panels) and zonal mean zonal wind (two bottom panels) at $75^{\circ} \mathrm{N}$ for 2007 and 2009 as a function of time and altitude. The meteorological conditions show remarkable differences between these two years. The winter of 2007 was rather stable whereas early 2009 was dynamically quite exceptional as the stratopause warmed and dropped below $30 \mathrm{~km}$ in late January. In early February the stratopause reformed around $80 \mathrm{~km}$, which led to very low temperatures between 30 and $50 \mathrm{~km}$. The same figure also shows that the warming in 2009 was accompanied by a rapid change in the direction of the zonal flow (from positive/westerly to negative/easterly), which persisted until early March. This one month period of easterly winds in 2009 led to low wave activity above the critical level, which for stationary waves corresponds to a level where the zonal wind speed equals to zero, and enabled the formation of a strong polar vortex, which did not break until early March. Changes in the wind direction took place also in early and late February 2007, but these changes lasted only for at most $\approx 10$ days. Extreme changes in stratopause temperatures, as in 2009, did not occur.

According to McInturff (1978), the criteria for a major SSW are fulfilled when the latitudinal mean temperature at $10 \mathrm{hPa}(\approx 30 \mathrm{~km})$ or below increases poleward of $60^{\circ} \mathrm{N}$ and the zonal winds are reversed from westerly to easterly in the same area. Figure 3 shows the zonal mean temperature and zonal mean zonal wind at $10 \mathrm{hPa}$ as a function of time and latitude. The poleward temperature gradient reversed during both winters. In 2007 the temperature increase was fairly small $(\approx 10 \mathrm{~K})$ and lasted only about 10 days. The warming in 2009 was more pronounced and the temperature gradient was positive for approximately 20 consecutive days in the polar region. The figure also shows that the zonal mean wind at $10 \mathrm{hPa}$ reversed from westerly to easterly at the same time when the temperature gradient became positive. This indicates that a major SSW occurred in both winters. However, the situation in 2007 returned to undisturbed winter conditions in a few days, which is more common for minor SSWs. In 2009 the wind reversal to westerly took about one month, giving enough time for the vortex to recover in the upper stratosphere/lower mesosphere. The criteria for a major SSW in 2009 were first met on the 24 January (black vertical dashed line).

It has been suggested by Manney et al. (2008) that the ECMWF operational analyses underestimate the variations in the stratopause altitude during extreme meteorological conditions. The operational analyses agree, however, well with satellite observations of MLS and SABER (Sounding of the Atmosphere using Broadband Emission Radiometry) in early winter stratopause temperatures. Compared to the MLS measurements (Manney et al., 2009) the ECMWF operational analyses underestimate the altitude of the stratopause reformation in 2009 by about $5 \mathrm{~km}$. The zonal wind, instead, resembles MLS measurements also at higher altitudes. Below $50 \mathrm{~km}$ altitude the MLS observations and operational analyses are in very good agreement. 


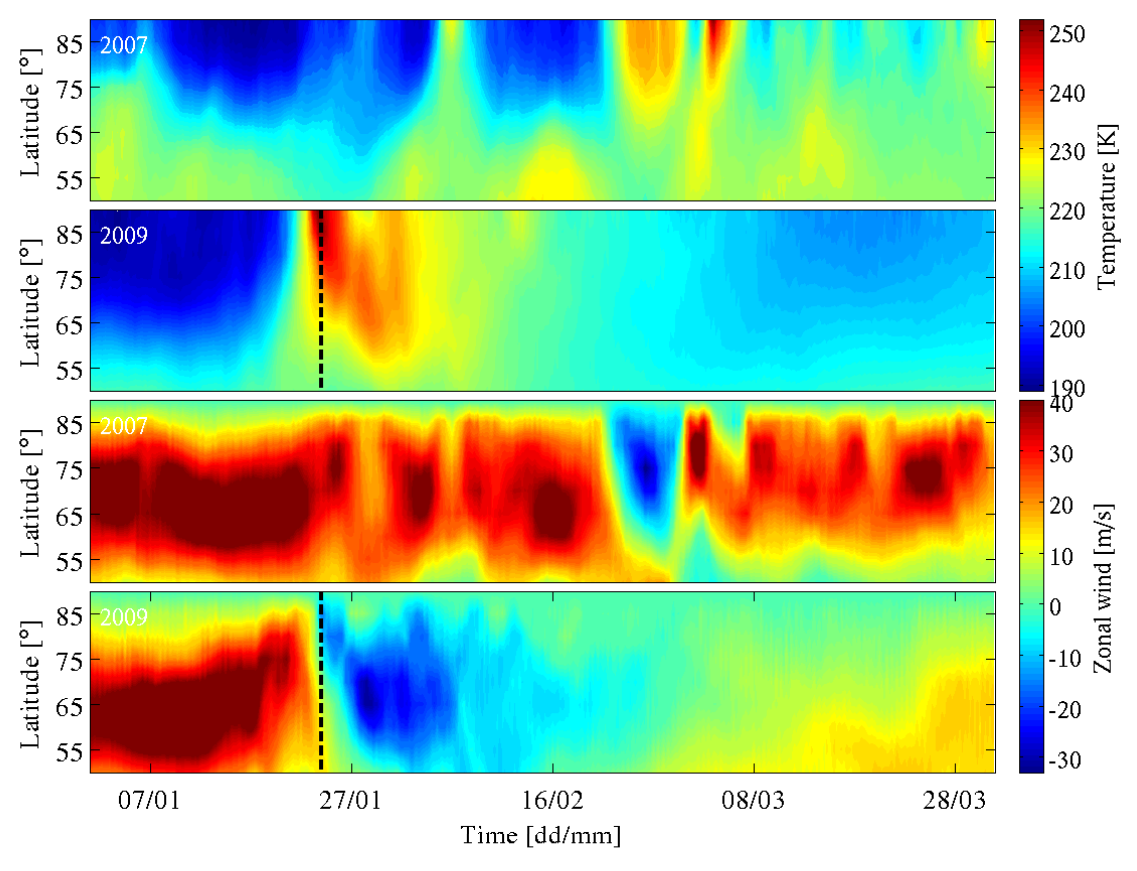

Fig. 3. ECMWF zonal mean temperature $(\mathrm{K})$ and zonal mean zonal wind $\left(\mathrm{m} \mathrm{s}^{-1}\right)$ at $10 \mathrm{hPa}(\approx 30 \mathrm{~km})$ as a function of time and latitude. The vertical black dashed lines in figures representing the year 2009 show the date when the criteria for the major SSW were fulfilled.

\subsection{NO $_{\mathrm{x}}$ descent}

Figure 4 presents $\mathrm{NO}_{\mathrm{x}}$ observations measured by ACE-FTS in 2007 (top) and 2009 (bottom). Plotted are daily medians north of $60^{\circ} \mathrm{N}$, which correspond to measurement locations shown in Fig. 1. The observations show that there were large differences in the distribution of $\mathrm{NO}_{\mathrm{x}}$ between years 2007 and 2009. In 2007 the mesospheric maximum of $\mathrm{NO}_{\mathrm{x}}$ reached $60-65 \mathrm{~km}$ in the beginning of the year and then ascended towards the spring. This can be explained by changes in the zonal mean temperature and wind fields (Figs. 2 and 3 ). The stratopause was quite stable until the beginning of February, when the temperatures increased for a few days and the westerly winds weakened. Warm midlatitude air with low $\mathrm{NO}_{\mathrm{x}}$ concentrations mixed with the colder polar air and decreased the $\mathrm{NO}_{\mathrm{x}}$ concentrations. This warming did not dislocate the stratopause and the temperatures remained quite high even after the warming. The warming in late February produced no significant effects on $\mathrm{NO}_{\mathrm{x}}$.

In contrast, the major SSW in 2009 had a great impact on $\mathrm{NO}_{\mathrm{x}}$. A tongue-like structure of descending $\mathrm{NO}_{\mathrm{x}}$ from the mesosphere to the stratosphere after the SSW is clearly seen in Fig. 4. High $\mathrm{NO}_{\mathrm{x}}$ amounts were transported from 80 to $55 \mathrm{~km}$ altitude in about 40 days. The descent took place during the recovery of the polar vortex and is also discussed by Randall et al. (2009). Comparison of $\mathrm{NO}_{\mathrm{x}}$ and isentrops calculated from ECMWF operational data indicates that the $\mathrm{NO}_{\mathrm{x}}$ concentration isolines crossed the isentrops (not shown), suggesting that the descent was diabatic. The situa- tion is thus similar to the upper stratospheric vortex recovery that occurred after a SSW in winter 2005/2006 (Manney et al., 2008). In mid-March the descent stopped and $\mathrm{NO}_{\mathrm{x}}$ concentrations decreased back to the level on which they were before the SSW. At this time the stratopause had already reformed and the zonal winds had started to reverse back to westerly (Fig. 2) allowing planetary waves to propagate upward, interact with the vortex, and mix the low- $\mathrm{NO}_{\mathrm{x}}$ air from outside the vortex with high- $\mathrm{NO}_{\mathrm{x}}$ air inside the vortex.

Figure 5 shows $\mathrm{NO}_{\mathrm{x}}$ timeseries calculated from FinROSECTM results. The data are daily means, calculated using only the grid points corresponding to ACE-FTS measurement locations (Fig. 1). The model reproduces the distribution of $\mathrm{NO}_{\mathrm{x}}$ reasonably well compared to the observations shown in Fig. 4. The maximum of $\mathrm{NO}_{\mathrm{x}}$ in the beginning of 2007 at about $75 \mathrm{~km}$ is of the same order of magnitude (800-900 ppb) as in the observations, but extends $3-5 \mathrm{~km}$ lower in the middle atmosphere. In 2009, the observations and model results show an increase of $\mathrm{NO}_{\mathrm{x}}$ to $150-200 \mathrm{ppb}$ at $65 \mathrm{~km}$. The modelled and observed $\mathrm{NO}_{\mathrm{x}}$ both descend to about $55 \mathrm{~km}$, but at this altitude the amount of $\mathrm{NO}_{\mathrm{x}}$ is underestimated in the model by $40-60 \mathrm{ppb}$. The descent also starts $3-5$ days earlier and lasts 3-5 days longer in the model than in the observations.

In order to test the robustness of the results, we averaged the model $\mathrm{NO}_{\mathrm{x}}$ over the whole polar cap $\left(60^{\circ} \mathrm{N}-90^{\circ} \mathrm{N}\right)$ instead of sampling at ACE locations, but found this to have only a slight effect on the results (not shown). Compared to the sampled results (Fig. 5) the descent stopped a couple 


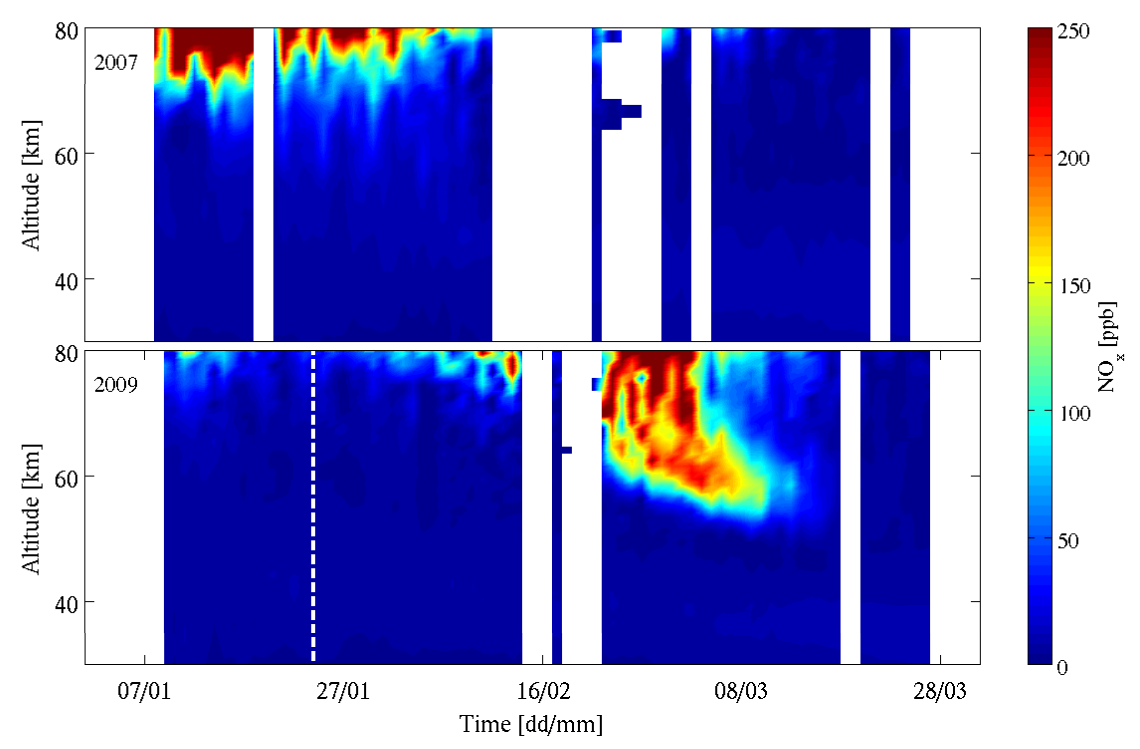

Fig. 4. $\mathrm{NO}_{\mathrm{x}}$ time series (ppb) as daily medians measured by ACE-FTS. White dashed line indicates the time point, when the criteria for the major SSW were fulfilled in 2009. The upper panel is for 2007 and the lower for 2009. White regions indicate missing data or not enough data.

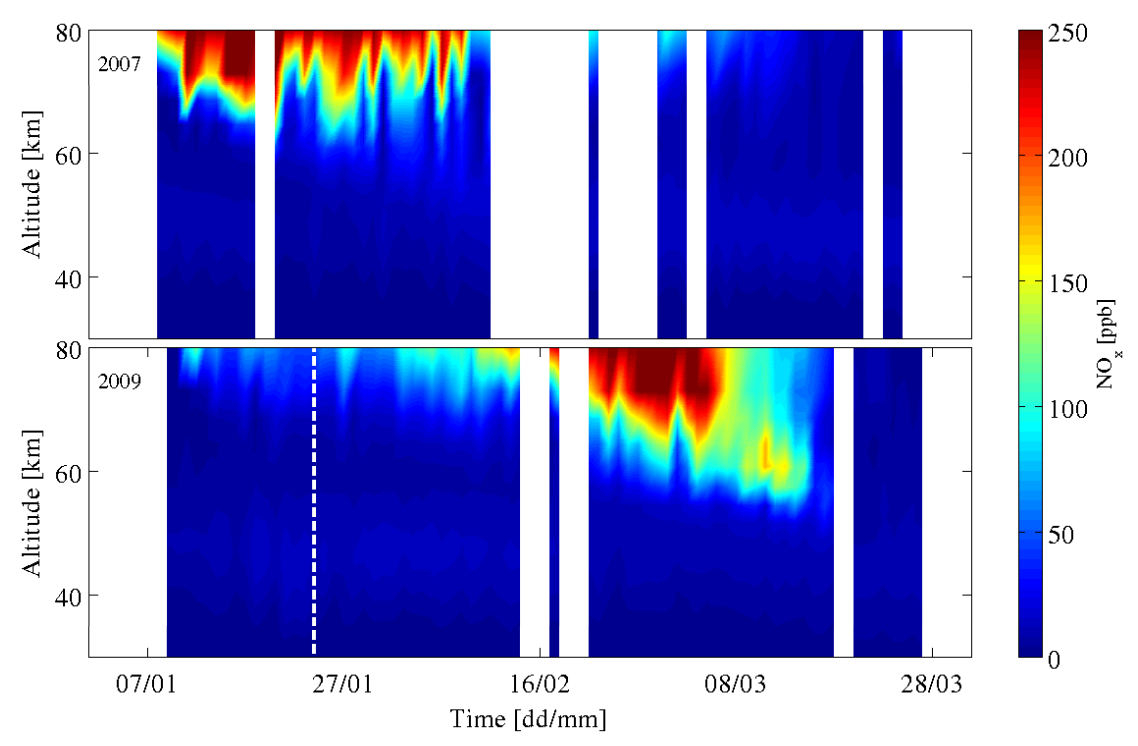

Fig. 5. $\mathrm{NO}_{\mathrm{x}}$ time series (ppb) as daily means from FinROSE-CTM. White dashed line indicates the time point, when the criteria for the major SSW were fulfilled in 2009. The upper panel is for 2007 and the lower for 2009. White regions indicate missing ACE-FTS data or not enough ACE-FTS data.

of days earlier above $60 \mathrm{~km}$, but continued longer until late March between 60 and $50 \mathrm{~km}$ with $\mathrm{NO}_{\mathrm{x}}$ mixing ratios of 50-100 ppb. Otherwise the concentrations were of the same magnitude as in the sampled results. The similarity between the sampled and whole-polar-cap results from the model suggests that $\mathrm{NO}_{\mathrm{x}}$ did not reach upper stratosphere anywhere in the polar cap region.

To estimate the effect of different UBCs on the $\mathrm{NO}_{\mathrm{x}}$ descent we made two additional model runs. In these runs we used the following upper boundaries: (1) a constant value ( $\sim 670 \mathrm{ppb}$ ) between the 11 February and the 4 March and (2) a two-step increment of $\mathrm{NO}_{\mathrm{x}}$ so that the first step $(\sim 190 \mathrm{ppb})$ is located between the 11 and 21 February and the second one $(\sim 540 \mathrm{ppb})$ between the 22 February and the 4 March. The results (not shown) for case 2 are in agreement with those obtained with the interpolated upper boundary shown in Fig. 1. In contrast, case 1 produces about $100 \mathrm{ppb}$ higher $\mathrm{NO}_{\mathrm{x}}$ mixing ratios between 60 and $80 \mathrm{~km}$ during the 


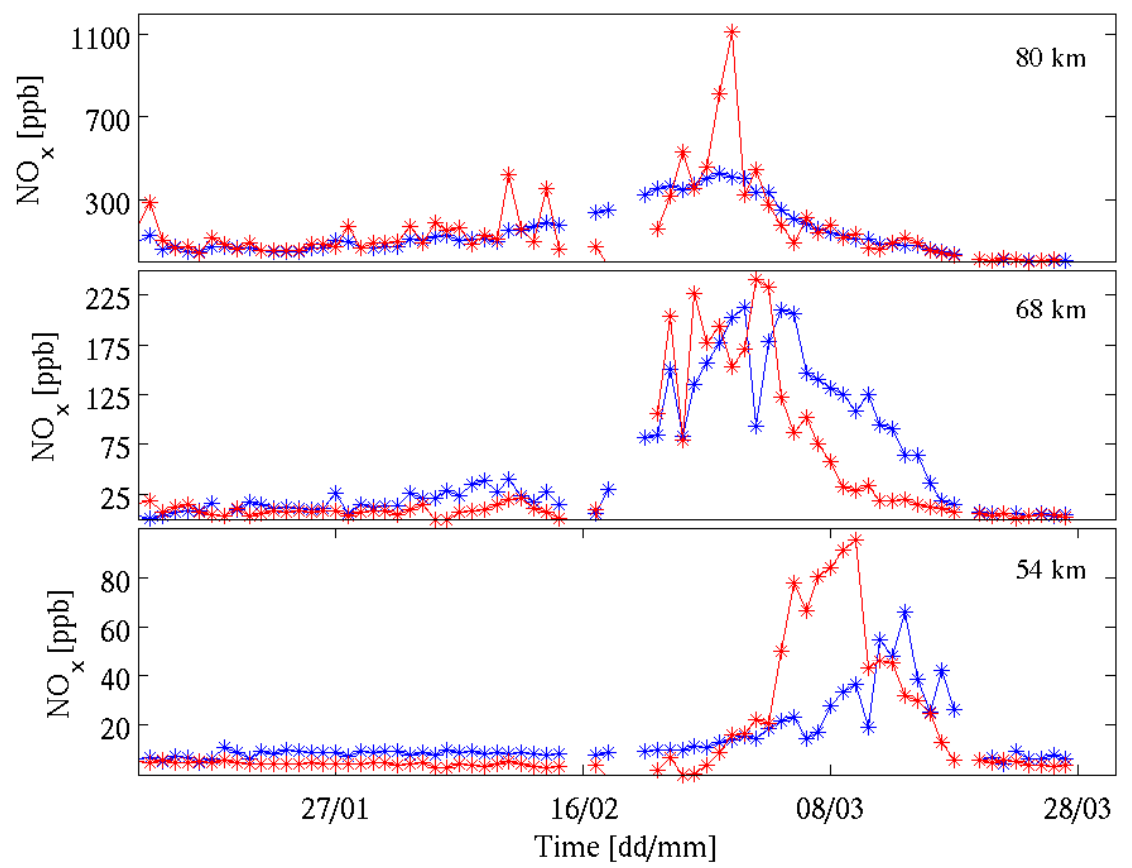

Fig. 6. ACE-FTS $\mathrm{NO}_{\mathrm{x}}$ observations (red line) and model results (blue line) in ppb at 80 (top), 68 (middle) and $54 \mathrm{~km}$ (bottom) altitudes as a function of time in 2009.

descent event until early March. At this time the mixing ratios are about $50 \mathrm{ppb}$ higher. However, $\mathrm{NO}_{\mathrm{x}}$ descent stops at the same altitude as with the interpolated upper boundary. As expected, the different upper boundaries change only the amount of descending $\mathrm{NO}_{\mathrm{x}}$ because in all model runs the descent is driven by the same ECMWF meteorological data.

Figure 6 shows the model results and ACE-FTS observations at 80,68 and $54 \mathrm{~km}$ altitudes. Differences at $80 \mathrm{~km}$ altitude during 10-28 February are due to the interpolated UBC at that time. However, the modified UBC improves the agreement between the model and observations at lower altitudes. There is a reasonable agreement between the model and the observations at $68 \mathrm{~km}$ altitude. An overestimation of about $100 \mathrm{ppb}$ occurs after the $8 \mathrm{March}$, consistent with the fact that the descent lasted longer in the model than observed by ACEFTS. Significant differences are found at $54 \mathrm{~km}$ where the model produces $40-60 \mathrm{ppb}$ smaller values than found in the observations. The observed maximum of $\mathrm{NO}_{\mathrm{x}}$ occurs about 10 days earlier compared to the model results. Overall, the model succeds to reproduce the descent of $\mathrm{NO}_{\mathrm{x}}$, with no insitu production included in the model, reasonably well compared to the observations and confirms the results of Randall et al. (2009) about the importance of dynamics on the distribution of $\mathrm{NO}_{\mathrm{x}}$. Although this is not a direct measure, the $\mathrm{NO}_{\mathrm{x}}$ comparison suggest that the ECMWF data are in this case usable in atmospheric modelling also at mesospheric altitudes.
Figure 7 illustrates the modelled distribution of $\mathrm{NO}_{\mathrm{x}}$ in the northern polar region $\left(50^{\circ} \mathrm{N}-90^{\circ} \mathrm{N}\right)$. The descending $\mathrm{NO}_{\mathrm{x}}$ reaches $69 \mathrm{~km}$ altitude already on 6 February with amounts of $80-100 \mathrm{ppb}$. The circular structure of $\mathrm{NO}_{\mathrm{x}}$ in the polar region is due to the existing or evolving polar vortex. The effect of photochemistry can be considered negligible during the polar winter on latitudes poleward of $60^{\circ} \mathrm{N}$. As Fig. 6 already showed, with time $\mathrm{NO}_{\mathrm{x}}$ is transported at lower altitudes with mixing ratios of $60-80 \mathrm{ppb}$ finally reaching $54 \mathrm{~km}$ on 15 March. ACE-FTS measurement locations are marked in the figure with filled white circles. As mentioned already in section 2.2 ACE-FTS makes about 10 measurements per day. In cases when some of the data are corrupted and excluded from the analysis, even fewer observations are left to represent the whole polar cap region. This might lead to differences between observations and the model results, especially close to the polar vortex edge. In addition, the closest model grid to ACE-FTS measurement covers by definition a larger area $\left(10^{\circ} \times 5^{\circ}\right)$ than the point-form observation does and can also be inside the vortex, although the measurement was made outside the vortex. This can partly explain the differences between the model and observations.

To estimate the effect of chemistry on descending $\mathrm{NO}_{\mathrm{x}}$, we have analysed the $\mathrm{NO}_{\mathrm{x}}$ tracer in the model. The tracer uses the same boundary condition as $\mathrm{NO}_{\mathrm{x}}$, but is not affected by chemistry. Transport is thus the only factor that affects the tracer. The relative effect of chemistry can be calculated by dividing the difference between $\mathrm{NO}_{\mathrm{x}}$ and the tracer with the 


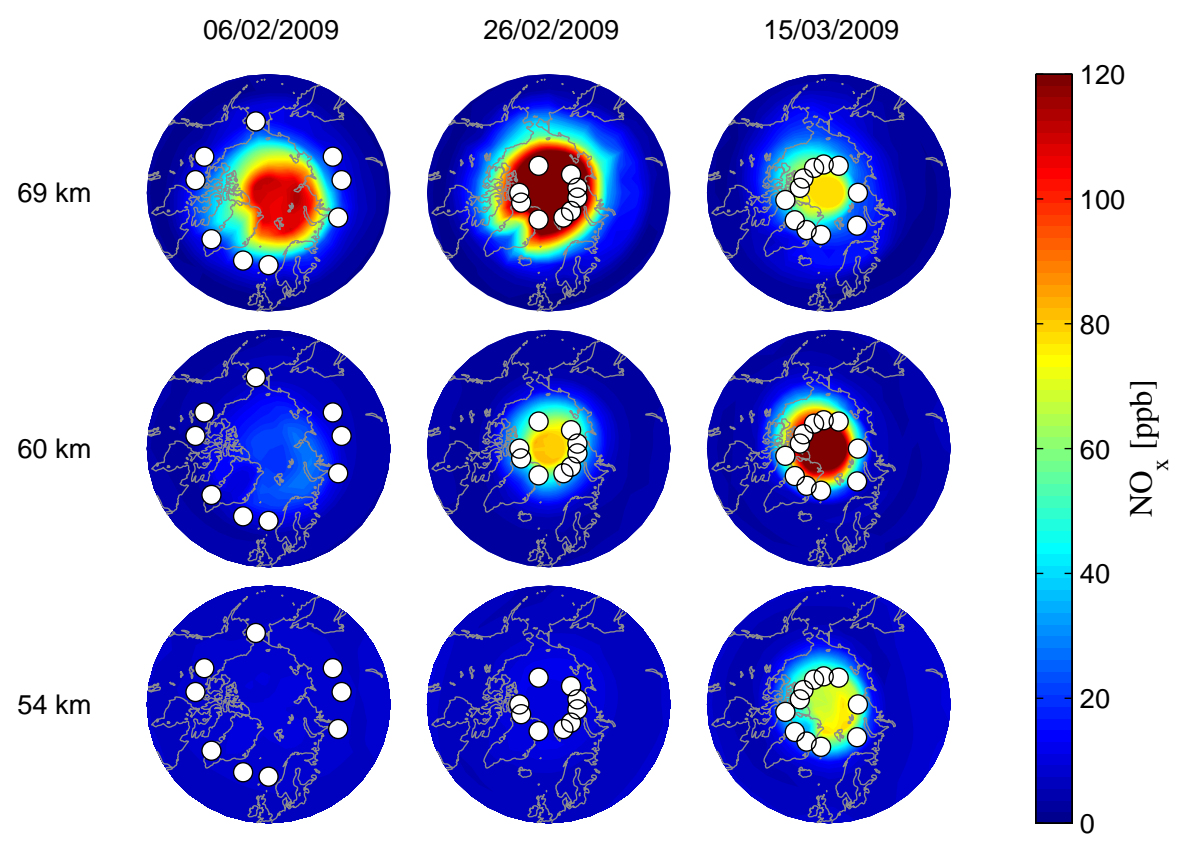

Fig. 7. Distribution of $\mathrm{NO}_{\mathrm{x}}$ in ppb at 69,60 and $51 \mathrm{~km}$ altitudes (rows) on 6 and 26 February and 15 March (columns) in the northern polar region $\left(50^{\circ} \mathrm{N}-90^{\circ} \mathrm{N}\right)$ calculated from the model results. White circles indicate the measurement locations of ACE-FTS on that particular day.

amount of $\mathrm{NO}_{\mathrm{x}}$. The model results indicate that the chemical production of $\mathrm{NO}_{\mathrm{x}}$ is not effective during polar winter and, furthermore, the relative chemical loss is only $3 \%$ or less (not shown), meaning that chemistry does not affect the $\mathrm{NO}_{\mathrm{x}}$ concentrations during the polar night. Therefore $\mathrm{NO}_{\mathrm{x}}$ can descend inside the arctic vortex with only little interference by chemistry. In addition to gas phase chemistry, also photodissociation processes affect the amount of $\mathrm{NO}_{\mathrm{x}}$ in the middle and upper atmosphere. The time period from January to March in the northern polar area is very dark leading to only weak photodissociation processes and thus to longer photochemical lifetimes. The photochemical lifetime of $\mathrm{NO}_{\mathrm{x}}$ was nearly two months in early January decreasing to about 5 days towards the end of March in the altitude range of 60$80 \mathrm{~km}$. This is a further evidence that $\mathrm{NO}_{\mathrm{x}}$ was mainly influenced by atmospheric dynamics during the time period under investigation.

\subsection{Effects on $\mathrm{O}_{3}$}

The descent event of $\mathrm{NO}_{\mathrm{x}}$ in 2009 was one of the strongest observed. If transported down to the stratosphere, $\mathrm{NO}_{\mathrm{x}}$ affects ozone balance through well-known catalytic reaction cycles (Grenfell et al., 2006). Although we do not expect to see any $\mathrm{NO}_{\mathrm{x}}$ related changes in stratospheric ozone in this case (the descending $\mathrm{NO}_{\mathrm{x}}$ did not reach stratosphere before vortex breakdown) we are interested in any effects this meteorological event might have had on ozone. Figure 8 shows
ACE-FTS observations and FinROSE model results of ozone in early 2009. Analysing the $\mathrm{O}_{\mathrm{x}}$ tracer in the model (not shown), similarly to the $\mathrm{NO}_{\mathrm{x}}$ tracer earlier, we find that the behaviour of ozone until mid-February, including ozone decrease in late January and early February, was largely determined by the dynamics. The model results show lower ozone mixing ratios around $40 \mathrm{~km}$ compared to the observations, which can partially be explained by the non-perfect correspondence of the closest model grid point with the daily median of the observations.

Both ACE-FTS and FinROSE show ozone decrease after mid-February 2009 starting from around $50 \mathrm{~km}$ (Fig. 8). The observations indicate a decrease of about $20 \%$ between 30 $50 \mathrm{~km}$ lasting one month and recovery in early March. In the model, ozone depletion is about $10 \%$ stronger than observed while the recovery takes place later in mid-March. Although coinciding with the $\mathrm{NO}_{\mathrm{x}}$ descent, the ozone decrease is not directly linked to the descent as discussed earlier. The dynamics could, on the other hand, lead to ozone decrease at $40 \mathrm{~km}$ through transport of low ozone concentrations from above. The $\mathrm{O}_{\mathrm{x}}$ tracer analysis, however, indicates that transport of air with low $\mathrm{O}_{\mathrm{x}}$ concentrations cannot explain its decrease. Similar to $\mathrm{NO}_{\mathrm{x}}$ descent, the descent of low $\mathrm{O}_{\mathrm{x}}$ air did not affect altitudes below $50 \mathrm{~km}$. Below $50 \mathrm{~km}$ the downward transport was too weak to explain the observed structure of ozone. In the model, ozone destroying substances, such as $\mathrm{HO}_{\mathrm{x}}$, bromine and chlorine, were produced after mid-February as the solar radiation increased and 


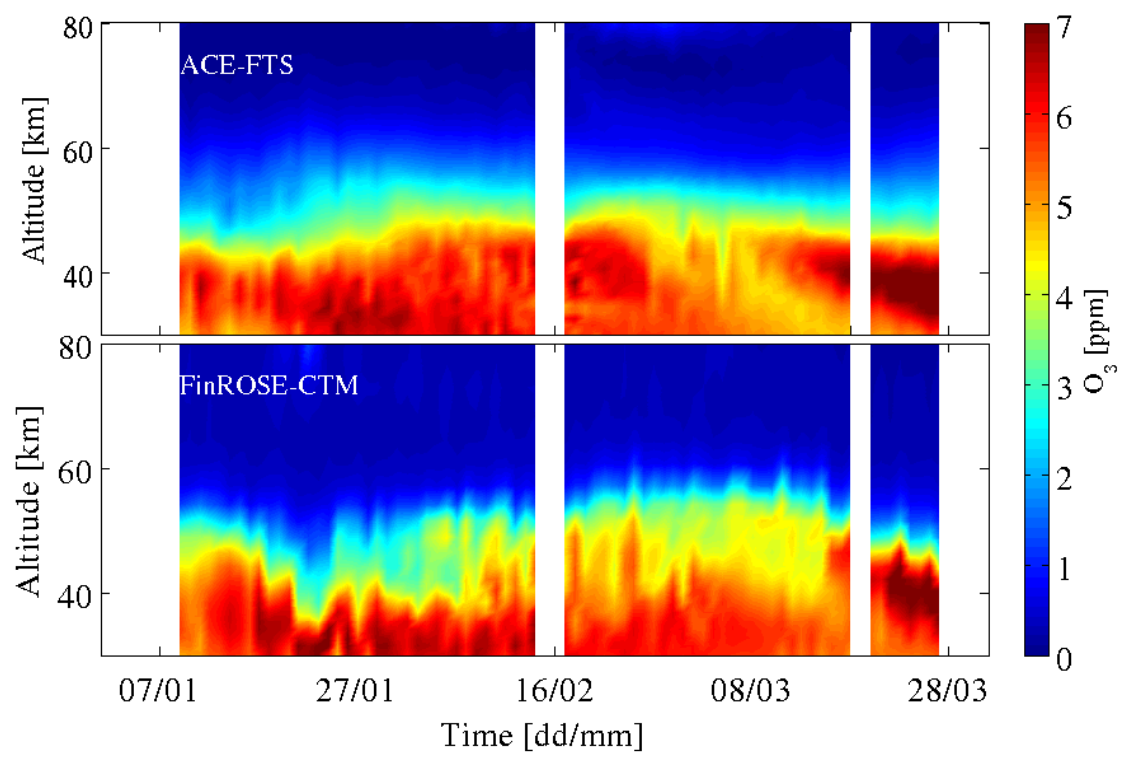

Fig. 8. ACE-FTS (top) and FinROSE-CTM (bottom) ozone time series in ppm as a function of altitude for early 2009 in ACE-FTS measurement locations.

the chemical processes, including photodissociation, started to play an important role on atmospheric composition. These substances, with the help of a strong polar vortex, enabled the catalytic cycles destroying ozone and caused the observed depletion at $40 \mathrm{~km}$. When the solar radiation increased, the production of ozone began to dominate. This led to increase of ozone in both the observations and model results in early March at $45 \mathrm{~km}$ altitude and then gradually also at lower altitudes as shown in Fig. 8.

\section{Discussion}

In the case of 2009, even though a strong descent event occurred, enhanced mesospheric $\mathrm{NO}_{\mathrm{x}}$ did not reach the upper stratosphere and thus did not affect ozone. The model results show this behaviour throughout the northern polar cap region, in agreement with the spatially limited ACE-FTS observations. However, based on a single case of descent presented in this paper, we cannot in general dismiss the possible connection between descending $\mathrm{NO}_{\mathrm{x}}$, upper stratospheric ozone decrease, and subsequent changes in dynamics. If the SSW had occurred earlier, $\mathrm{NO}_{\mathrm{x}}$ would have had more time to descend and reach the stratosphere before the vortex break-up/split. According to the model results, $\mathrm{NO}_{\mathrm{x}}$ rapidly descended from mesosphere to stratosphere with a velocity of about $700 \mathrm{~m} \mathrm{day}^{-1}$ in February and early March 2009. In contrast, average descent rates in the polar vortex are typically less than $200 \mathrm{~m}$ day $^{-1}$. Assuming velocity of $700 \mathrm{~m} \mathrm{day}^{-1}$, the descent should have started 1030 days earlier in order to reach $50-35 \mathrm{~km}$ altitude.
We would like to point out that Randall et al. (2009) and Vogel et al. (2008) have shown that the observed ozone loss in early 2004 can be attributed to a $\mathrm{NO}_{\mathrm{x}}$ descent event similar to that of 2009. Compared to the 2009 event, the SSW that caused the $\mathrm{NO}_{\mathrm{x}}$ descent in early 2004 occurred about one month earlier, i.e. in late December, allowing enhanced $\mathrm{NO}_{\mathrm{x}}$ to reach the stratosphere. Therefore, strong $\mathrm{NO}_{\mathrm{x}}$ descent events seem to decrease stratospheric ozone only if the corresponding SSW occurs early enough in the winter period (by early January), although this time condition would obviously be relaxed if in-situ production of $\mathrm{NO}_{\mathrm{x}}$ by energetic particle precipitation occurred at altitudes below $80 \mathrm{~km}$. If the SSW occurred later than early January, it might actually lead to weaker connection between MLT $\mathrm{NO}_{\mathrm{x}}$ production and stratospheric ozone, i.e. any enhanced $\mathrm{NO}_{\mathrm{x}}$ amounts already in the mesosphere would be mixed with outside-vortex air during the SSW, and the after-SSW descent would start too late to transport $\mathrm{NO}_{\mathrm{x}}$ from the upper mesosphere to the stratosphere, as in the case of the 2009 descent event. In such conditions, the effect of EEP-NO $\mathrm{NO}_{\mathrm{x}}$ on stratospheric ozone in SSW years could be equal or smaller compared to years without a SSW. This could be one potential reason for the findings of Lu et al. (2008) and Seppälä et al. (2009), who have demonstrated that changes in stratospheric and tropospheric dynamics actually correlate with geomagnetic Ap index better when the SSW-years were excluded from their analyses. It is evident to us that more research is needed to answer the questions concerning $\mathrm{NO}_{\mathrm{x}}-\mathrm{O}_{3}$ interaction and possible connection to stratospheric/tropospheric dynamics. 


\section{Conclusions}

In this paper, we have used the FinROSE-CTM and ACEFTS observations to study the effect of polar vortex dynamics on the distribution of $\mathrm{NO}_{\mathrm{x}}$ in the winter polar region. Two different Northern Hemisphere cases, 2007 and 2009, were considered. The latter was characterized by a strong $\mathrm{NO}_{\mathrm{x}}$ descent event in February-March, which begun after a record-breaking SSW. In the modelling, we used ECMWF operational winds, temperature, and pressure up to $0.01 \mathrm{hPa}$ $(\sim 80 \mathrm{~km})$ and a $\mathrm{NO}_{\mathrm{x}}$ upper boundary at $80 \mathrm{~km}$ based on ACE-FTS observations, and then compared the results with the observations at lower altitudes.

In contrast to 2007, when a SSW did not have any significant effects on the atmospheric composition, in 2009 large amounts of $\mathrm{NO}_{\mathrm{x}}$ descended from the upper mesosphere to the stratosphere following a major SSW. Analysis of ECMWF data shows that the descent was enabled by the formation of a strong polar vortex facilitated by easterly zonal flow that prevented the vertical propagation of planetary waves. Based on ACE-FTS observations, the $\mathrm{NO}_{\mathrm{x}}$ descent continued until mid-March, by which time the high- $\mathrm{NO}_{\mathrm{x}}$ amounts of 150 $200 \mathrm{ppb}$ reached down to $55 \mathrm{~km}$. The FinROSE-CTM results are in reasonable agreement with ACE-FTS, except that the amount of $\mathrm{NO}_{\mathrm{x}}$ at $55 \mathrm{~km}$ is underestimated by $40-60 \mathrm{ppb}$ compared to the observations. Although the ACE-FTS observations have a restricted spatial coverage, the model results indicate that the measurements give a good representation of the $\mathrm{NO}_{\mathrm{x}}$ descent throughout the polar cap. The FinROSECTM results also show that chemical production and loss of $\mathrm{NO}_{\mathrm{x}}$ was insignificant during the descent in the polar night region, so that $\mathrm{NO}_{\mathrm{x}}$ distribution was controlled by the vortex dynamics. The reasonably good agreement between observations and the model gives confidence in the usability of the ECMWF operational data in mesospheric modelling.

Although a strong descent event occurred in FebruaryMarch 2009 after a major SSW, we find that in this case the high $\mathrm{NO}_{\mathrm{x}}$ amounts did not reach upper stratosphere and thus did not catalytically deplete ozone. Instead, both ACE-FTS and FinROSE-CTM show ozone decreased by about $20 \%$ at $30-50 \mathrm{~km}$ in late February-early March, which according to the model was due to increasing amount of solar radiation and activation of $\mathrm{HO}_{\mathrm{x}}$ and halogen compounds. However, if a similar descent event had begun about a month earlier, $\mathrm{NO}_{\mathrm{x}}$ would have reached stratospheric altitudes. Therefore, it seems that a connection between EEP-NO ${ }_{x}$ production in the MLT region and stratospheric ozone variability requires suitable timing of descent events, and our case study does not exclude the possibility of this connection. More research on $\mathrm{EPP}-\mathrm{NO}_{\mathrm{x}}$ and stratospheric ozone is needed, keeping in mind the links to dynamics and ground-level temperature and pressure anomalies that have been suggested.
Acknowledgements. S.-M. Salmi would like to thank Viktoria Sofieva for helpful comments. All the authors thank also Cora Randall, Lynn Harvey and Kaley Walker for their help with the ACE-FTS data. Funding from the Academy of Finland through the THERMES, SPOC, SAARA and MIDAT projects is gratefully acknowledged. A. Seppälä was supported by the European Commission project FP7-PEOPLE-IEF-2008/237461. The Atmospheric Chemistry Experiment (ACE) data were provided by the European Space Agency (ESA). ACE is a Canadian-led mission mainly supported by the Canadian Space Agency and the Natural Sciences and Engineering Research Council of Canada.

Edited by: A. J. G. Baumgaertner

\section{References}

Arnold, N. F. and Robinson, T. R.: Solar magnetic flux influences on the dynamics of the winter middle atmosphere, Geophys. Res. Lett., 28(12), 2381-2384, doi:10.1029/2000GL012825, 2001.

Barth, C. A.: Nitric oxide in the lower thermosphere, Planet. Space Sci., 40, 315-336, 1992.

Baumgaertner, A. J. G., Jöckel, P., and Brühl, C.: Energetic particle precipitation in ECHAM5/MESSy1 - Part 1: Downward transport of upper atmospheric NOx produced by low energy electrons, Atmos. Chem. Phys., 9, 2729-2740, doi:10.5194/acp-92729-2009, 2009.

Baumgaertner, A. J. G., Seppälä, A., Jöckel, P., and Clilverd, M. A.: Geomagnetic activity related NOx enhancements and polar surface air temperature variability in a chemistry climate model: modulation of the NAM index, Atmos. Chem. Phys. Discuss. 10, 30171-30203, doi:10.5194/acpd-10-30171-2010, 2010.

Bernath, P. F., McElroy, C. T., Abrams, M. C., Boone, C. D., Butler, M., Camy-Peyret, C., Carleer, M., Clerbaux, C., Coheur, P.-F., Colin, R., DeCola, P., DeMaziére, M., Drummond, J. R., Dufour, D., Evans, W. F. J., Fast, H., Fussen, D., Gilbert, K., Jennings, D. E., Llewellyn, E. J., Lowe, R. P., Mahieu, E., McConnell, J. C., McHugh, M., McLeod, S. D., Michaud, R., Midwinter, C., Nassar, R., Nichitiu, F., Nowlan, C., Rinsland, C. P., Rochon, Y. J., Rowlands, N., Semeniuk, K., Simon, P., Skelton, R., Sloan, J. J., Soucy, M.-A., Strong, K., Tremblay, P., Turnbull, D., Walker, K. A., Walkty, I., Wardle, D. A., Wehrle, V., Zander, R., and Zou, J.: Atmospheric Chemistry Experiment (ACE): Mission overview, Geophys. Res. Lett., 32, L15S01, doi:10.1029/2005GL022386, 2005.

Callis, L. B. and Lambeth, J. D.: $\mathrm{NO}_{\mathrm{y}}$ formed by precipitating electron events in 1991 and 1992: Descent into the stratosphere as observed by ISAMS, Geophys. Res. Lett., 25, 1875-1878, doi:10.1029/98GL01219, 1998.

Callis, L. B., Natarajan, M., and Lambeth, J. D.: Calculated upper stratospheric effects of solar UV flux and $\mathrm{NO}_{\mathrm{y}}$ variations during the 11-year solar cycle, Geophys. Res. Lett., 27(23), 3869-3872, doi:10.1029/2000GL011622, 2000.

Callis, L. B., Natarajan, M., and Lambeth, J. D.: Solar-atmospheric coupling by electrons (SOLACE) 3, Comparisons of simulations and observations, 1979-1997, issues and implications, J. Geophys. Res., 106, 7523-7539, doi:10.1029/2000JD900615, 2001.

Clilverd, M. A., Seppälä, A., Rodger, C. J., Verronen, P. T., and Thomson, N. R.: Ionospheric evidence of thermosphere- 
to-stratosphere descent of polar $\mathrm{NO}_{\mathrm{x}}$, Geophys. Res. Lett., 33, L19811, doi:10.1029/2006GL026727, 2006.

Damski, J., Thölix, L., Backman, L., Taalas, P. and Kulmala, M.: FinROSE - middle atmospheric chemistry transport model, Boreal Env. Res., 12, 535-550, 2007.

Funke, B., Lopéz-Puertas, M., Gil-López, S., von Clarmann, T., Stiller, G. P., Fischer, H., and Kellmann, S.: Downward transport of upper atmospheric $\mathrm{NO}_{\mathrm{x}}$ into the polar stratosphere and lower mesosphere during the Antarctic 2003 and Arctic 2002/2003 winters, J. Geophys. Res., 110, D24308, doi:10.1029/2005JD006463, 2005.

Funke, B., Lopéz-Puertas, M., Fischer, H., Stiller, G. P., von Clarmann, T., Wetzel, G., Carli, B., and Belotti, C.: Comment on "Origin of the January-April 2004 increase in stratospheric $\mathrm{NO}_{2}$ observed in northern polar latitudes", by: JeanBaptiste Renard et al., Geophys. Res. Lett., 34, L07813, doi:10.1029/2006GL027518, 2007.

Grenfell, J. L., Lehmann, R., Mieth, P., Langematz, U., and Steil, B.: Chemical reation pathways affecting stratospheric and mesospheric ozone, J. Geophys. Res., 111, D17311, doi:10.1029/2004JD005713, 2006.

Hauchecorne, A., Bertaux, J.-L., Dalaudier, F., Russell III, J. M., Mlynczak, M. G., Kyrölä, E., and Fussen, D., : Large increase of $\mathrm{NO}_{2}$ in the north polar mesosphere in January-February 2004: Evidence of a dynamical origin from GOMOS/ENVISAT and SABER/TIMED data, Geophys. Res. Lett., 34, L03810, doi:10.1029/2006GL027628, 2007.

Kylling, A., Albold, A. and Seckmeyer, G.: Transmittance of a cloud is wavelength - dependent in the UV-range: Physical interpretation, Geophys. Res. Lett., 24(4), 397-400, doi:10.1029/97GL00111, 1997.

Langematz, U., Grenfell, J. L., Matthes, K., Mieth, P., Kunze, M., Steil, B., and Brühl, C.: Chemical effects in 11-year solar cycle simulations with the Freie Universität Berlin Climate Middle Atmosphere Model with online chemistry (FUB-CMAM-CHEM), Geophys. Res. Lett., 32, L13803, doi:10.1029/2005GL022686, 2005.

Lu, H., Clilverd, M. A., Seppälä, A., and Hood, L. L.: Geomagnetic perturbations on stratospheric circulation in late winter and spring, J. Geophys. Res., 113, D16106, doi:10.1029/2007JD008915, 2008.

Manney, G. L., Daffer, W. H., Strawbridge, K. B., Walker, K. A., Boone, C. D., Bernath, P. F., Kerzenmacher, T., Schwartz, M. J., Strong, K., Sica, R. J., Krüger, K., Pumphrey, H. C., Lambert, A., Santee, M. L., Livesey, N. J., Remsberg, E. E., Mlynczak, M. G., and Russell III, J. R.: The high Arctic in extreme winters: vortex, temperature, and MLS and ACE-FTS trace gas evolution, Atmos. Chem. Phys., 8, 505-522, doi:10.5194/acp-8-505-2008, 2008.

Manney, G. L., Schwartz, M. J., Krüger, K., Santee, M. L., Pawson, S., Lee, J. N., Daffer, W. H., Fuller, R. A., and Livesey, N. J.: Aura Microwave Limb Sounder observations of dynamics and transport during the record-breaking 2009 Arctic stratosphere major warming, Geophys. Res. Lett., 36, L12815, doi:10.1029/2009GL038586, 2009.
McInturff, R.: Stratospheric warmings: Synoptic, dynamic and general-circulation aspects, NASA Reference Publ. NASA-RP1017, NASA, Natl. Meteorol. Cent., Washington, DC, 1978.

Randall, C. E., Harvey, V. L., Siskind, D. E., France, J., Bernath, P. F., Boone, C. D., and Walker, K. A.: $\mathrm{NO}_{\mathrm{X}}$ descent in the Arctic middle atmosphere in early 2009, Geophys. Res. Lett., 36, L18811, doi:10.1029/2009GL039706, 2009.

Reddmann, T., Ruhnke, R., Versick, S., and Kouker, W.: Modeling disturbed stratospheric chemistry during solar-induced $\mathrm{NO}_{\mathrm{x}}$ enhancements observed with MIPAS/ENVISAT, J. Geophys. Res., 115, D00I11, doi:10.1029/2009JD012569, 2010.

Rozanov, E., Callis, L., Schlesinger, M., Yang, F., Andronova, N., and Zubov, V.: Atmospheric response to $\mathrm{NO}_{\mathrm{y}}$ source due to energetic electron precipitation, Geophys. Res. Lett., 32, L14811, doi:10.1029/2005GL023041, 2005.

Sander, S. P., Friedl, R. R., Golden, D. M., Kurylo, M. J., Moortgat, G. K., Keller-Rudek, H., Wine, P. H., Ravishankara, A. R., Kolb, C. E., Molina, M. J., Finlayson-Pitts, B. J., Huie, R. E., and Orkin, V. L.: Chemical kinetics and photochemical data for Use in Atmospheric Studies, Evaluation Number 15, Publication 06-2, JPL, Pasadena, USA, 2006.

Seppälä, A., Verronen, P. T., Clilverd, M. A., Randall, C. E., Tamminen, J., Sofieva, V., Backman, L., and Kyrölä, E.: Arctic and Antarctic polar winter $\mathrm{NO}_{\mathrm{x}}$ and energetic particle precipitation in 2002-2006, Geophys. Res. Lett., 34, L12810, doi:10.1029/2007GL029733, 2007.

Seppälä, A., Randall, C., Clilverd, M. A., Rozanov, E., and Rodger, C. J.: Geomagnetic activity and polar surface air temperature variability, J. Geophys. Res., 114, A10312, doi:10.1029/2008JA014029, 2009.

Siskind, D. E., Bacmeister, J. T., Summers, M. E., and Russell III, J. M.: Two-dimensional model calculations of nitric oxide transport in the middle atmosphere and comparison with Halogen Occultation Experiment data, J. Geophys. Res., 102, 3527-3546, doi:10.1029/96JD02970, 1997.

Solomon, S., Crutzen, P. J., and Roble, R. G.: Photochemical coupling between the thermosphere and the lower atmosphere: 1. odd nitrogen from 50 to 120 km, J. Geophys. Res., 87(C9), 7206-7220, 1982.

Vitt, F. M., Armstrong, T. P., Cravens, T. E., Dreschhoff, A. M., Jackman, C. H., and Laird, C. M.: Computed contributions to odd nitrogen concentrations in the Earth's polar middle atmosphere by energetic charged particles, J. Atmos. Sol.-Terr. Phys., 62, 669-683, 2000.

Vogel, B., Konopka, P., Grooß, J.-U., Müller, R., Funke, B., LópezPuertas, M., Reddmann, T., Stiller, G., von Clarmann, T., and Riese, M.: Model simulations of stratospheric ozone loss caused by enhanced mesospheric $\mathrm{NO}_{\mathrm{x}}$ during Arctic Winter 2003/2004, Atmos. Chem. Phys., 8, 5279-5293, doi:10.5194/acp-8-52792008, 2008. 